\title{
Investment Decision Model via an improved BP neural network
}

\author{
Jihong Shen ${ }^{1}$, Canxin Zhang ${ }^{2}$, Chunbo Lian ${ }^{1}$, Hao $\mathrm{Hu}^{1}$ and Musa Mammadov ${ }^{3}$ \\ ${ }^{1 .}$ College of Science \\ Harbin Engineering University \\ Harbin 150001, P.R.China \\ ${ }^{3 .}$ School of Information Technology and \\ Mathematics Science \\ University of Ballarat \\ Ballarat 3350, Austrilia
}

shenjihong@hrbeu.edu.cn

\begin{abstract}
In macro investment, an investment decision model is established by using an improved back propagation (BP) artificial neural network (ANN). In this paper, the relations between elements of investment and output of products are determined, and then the optimal distribution of investment is determined by adjusting the distributions rationally. This model can reflect the highly nonlinear mapping relations among each element of investment by using nonlinear utility functions to improve the architecture of artificial neural network, which can be widely applied in investment problems.
\end{abstract}

Index Terms - Artificial neural network; Nonlinear function approximation; Model of optimal distribution of investment.

\section{INTRODUCTION}

Investment is a significant method to implement longterm social resources allocation, to improve national economic productivity, and to expand production scale, as in [1]. Effective and efficient investment can boost the economy and promote social development, as in [2]. Accordingly, research on the investment decision is universally concerned and it has got many achievements, as in [3]-[6]. Through systematic analysis, investment can be rationally structured and efficiently utilized, which is able to stimulate economic growth.

In 1974, P.Werbos first proposed a learning algorithm for multilayer neural network in his doctoral dissertation [7]. However, it wasn't until 1986, through the book Parallel Distributed Processing written by a group called PDP (parallel distributed procession), that the BP algorithm gained recognition, and it led to a renaissance in the field of artificial neural network (ANN). Since then, ANN research rapidly became popular in artificial intelligence, economic and financial prediction, robotics and many other fields, as in [8][10]. Many experiments show that ANN can be better than some traditional methods, e.g. [11]. There has been a good deal of research on investment decision via ANN in recent years. Synergetic neural network is applied to build an investment model in [12]. Fuzzy ANN is used in [13]. Reference [14] describes an embedded grey system artificial neural network method to the investment.

In this paper, investment decision model based on an improved BP ANN is established by analyzing elements of investment, output of products and other information. The organization of this paper is as follows. In Section II, the structure of standard BP ANN is presented briefly. In Section III the architecture of BP ANN is improved by using nonlinear utility functions. ANN model of investment distribution is established in Section IV. In Section $\mathrm{V}$ and VI , computational experiments are shown as well as their results.

\section{THE ERROR BACK PROPAGATION NEUTRAL NETWORK}

The BP, one of the most popular techniques in the filed of $\mathrm{ANN}$, is a kind of supervised learning neural network, the principle behind which involves using the steepest gradient descent method and its improved methods to reach any small approximation. A general model of the BP neuron has a structure as depicted in Fig. 1.

Generally there are three layers contained in BP: input layer, hidden layer and output layer. Assume that there are $n$ input neurons, one hidden neuron $(\mathrm{m}=1)$ and one output neuron, we can infer a training process described by the following equations to update the weighted values, which can be divided into two stages:

(I)Hidden layer stage:

$$
n e t=\sum_{i=1}^{n} w_{i} x_{i}+b,(i=1,2, \ldots, n)
$$

where $w_{i}(i=1,2, \ldots, n)$ is a weighted value, $\mathrm{b}$ is a threshold value.

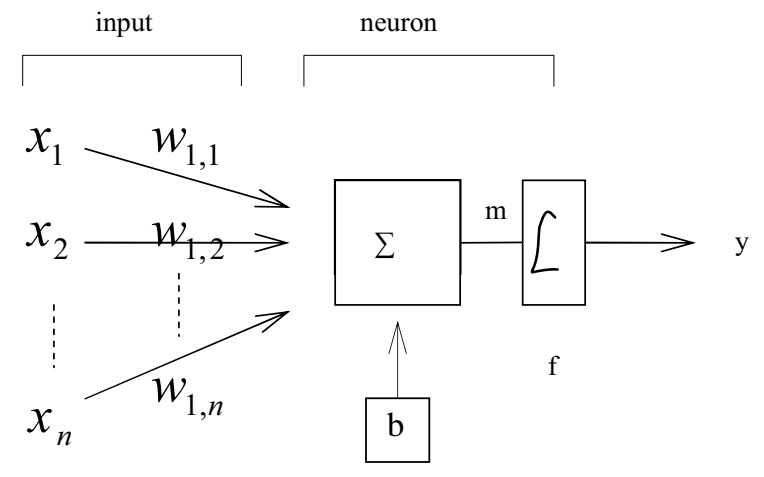

Fig.1 Model of the BP neuron 


$$
y=f_{H}(n e t)
$$

Here, $\mathrm{y}$ is the output, $f_{H}$ is called the activation function, usually a sigmoid function as follows:

$$
f_{H}(\text { net })=\log \operatorname{sig}(\text { net })=\frac{1}{1+\exp (-n e t)},
$$

which is called unipolar sigmoid function, or

$$
f_{H}(\text { net })=\tan \operatorname{sig}(n e t)=\frac{1-\exp (-n e t)}{1+\exp (-n e t)}
$$

which is called bipolar sigmoid function.

(II)Output stage:

$$
O=f_{O}(y)
$$

Here $f_{O}$ is the activation function, usually a line function.

In this paper, we have

$$
O=f_{O}(y)=y=f_{H}(\text { net }) .
$$

MSE (Mean Square Error) is selected as our search objective and is detailed as follow:

$$
M S E=\frac{1}{N} \sum_{i=1}^{N}(\text { true }- \text { output })^{2} .
$$

Here, true presents the authentic values known to users already, output is the output values of the BP artificial neural network after various algorithm training, and $\mathrm{N}$ presents the number of samples. Our goal is to minimize the $M S E$ through BP.

Now the optimization problem is formulated as

$$
\begin{aligned}
& \min \quad \frac{1}{N} \sum_{j=1}^{N}\left(g_{j}-f_{j}\left(\sum_{i=1}^{n} w_{i} x_{i}+b\right)\right)^{2}, \\
& \text { s.t. } \quad w_{i} \in[0,1],(i=1,2, \ldots, n), \quad b \in R .
\end{aligned}
$$

\section{IMPROVE THE ARCHITECTURE OF BP ANN WITH UTILITY FUNCTIONS}

Data from a certain investment and gross output have

\begin{tabular}{|c|c|c|c|c|c|}
\hline \multirow{2}{*}{ Year } & \multicolumn{4}{|c|}{ Investment } & \multirow{2}{*}{$\begin{array}{l}\text { Gross } \\
\text { output }\end{array}$} \\
\hline & 1st industry & 2nd industry & 3rd industry & sum & \\
\hline 1996 & 30.8 & 290.8 & 247.0 & 568.6 & 2380.9 \\
\hline
\end{tabular}
been collected in TABLE I.

In this problem, three investment values on different industries are taken as the three input neurons, the gross output value is taken as the output neuron, the number of samples is $8(\mathrm{~N}=8)$.

TABLE I

Original data

\begin{tabular}{|l|l|l|l|l|l|}
\hline 1997 & 38.9 & 343.2 & 287.8 & 669.9 & 2531.8 \\
\hline 1998 & 50.8 & 337.1 & 413.7 & 801.6 & 2765.7 \\
\hline 1999 & 58.2 & 308.1 & 419.6 & 785.9 & 3021.3 \\
\hline 2000 & 41.2 & 353.6 & 464.4 & 859.2 & 3300.5 \\
\hline 2001 & 55.8 & 350.1 & 573.8 & 979.7 & 3605.5 \\
\hline 2002 & 71.7 & 367.2 & 647.4 & 1086.3 & 3938.6 \\
\hline 2003 & 83.2 & 415.7 & 742.1 & 1241.0 & 4302.5 \\
\hline
\end{tabular}

We simplify TABLE I as follow:

TABLE II

Simplified data

\begin{tabular}{|c|c|c|c|c|}
\hline \multirow{2}{*}{ Year } & \multicolumn{3}{|c|}{ Investment } & $\begin{array}{c}\text { Gross } \\
\text { output }\end{array}$ \\
\cline { 2 - 4 }$Y_{1}$ & $a_{11}$ & $a_{12}$ & $a_{13}$ & $g_{1}$ \\
$Y_{2}$ & $a_{21}$ & $a_{22}$ & $a_{23}$ & $g_{2}$ \\
$\cdot$ & $\cdot$ & $\cdot$ & $\cdot$ & $\cdot$ \\
$\cdot$ & $\cdot$ & $\cdot$ & $\cdot$ & $\cdot$ \\
$\cdot$ & $\cdot$ & $\cdot$ & $\cdot$ & $\cdot$ \\
$Y_{8}$ & $a_{81}$ & $a_{82}$ & $a_{83}$ & $g_{8}$ \\
\hline
\end{tabular}

The structure can be formulated as

$$
f\left(w_{1} \vec{a}_{1}+w_{1} \vec{a}_{2}+w_{3} \vec{a}_{3}+b\right)=\vec{g},
$$

where

$$
f(t)=\log \operatorname{sig}(t) \text {, or } f(t)=\tan \operatorname{sig}(t),
$$

$w_{i} \in[0,1], i=(1,2,3)$ is a weighted value, $\mathrm{b}$ is a threshold value,

$$
\vec{a}_{i}=a_{j i}(i=1,2,3, j=1,2, \ldots, 8)
$$

is a vector group of investment,

$$
\vec{g}=g_{j}(j=1,2, \ldots, 8)
$$

is a vector group of gross output.

Here, (1), (2), can be formulated as

$$
\begin{array}{ll}
\min & \frac{1}{8} \sum_{j=1}^{8}\left(g_{j}-f\left(w_{1} a_{j 1}+w_{2} a_{j 2}+w_{3} a_{j 3}+b\right)\right)^{2}, \\
\text { s.t. } & w_{i} \in[0,1],(i=1,2,3) ; b \in R
\end{array}
$$

We can transform (4), (5), in this form:

$$
\begin{aligned}
\min \frac{1}{8} \sum_{j=1}^{8}\left(g_{j}-f\left(\left[w_{1} a_{j 1}+b_{1}\right]\right.\right. & +\left[w_{2} a_{j 2}+b_{2}\right] \\
& \left.\left.+\left[w_{3} a_{j 3}+b_{3}\right]\right)\right)^{2}
\end{aligned}
$$

s.t. $\quad w_{i} \in[0,1],(i=1,2,3) ; b \in R$. 
Here, we replace $\left[w_{i} \vec{a}_{i}+b_{i}\right]$ with nonlinear utility function $u\left(\vec{a}_{i}\right)$ :

$$
\begin{aligned}
& u\left(\vec{a}_{i}\right)=C_{i} \log \operatorname{sig}\left(A_{i} \vec{a}_{i}+B_{i}\right) \\
& =\frac{C_{i}}{1+\exp \left(A_{i} \vec{a}_{i}+B_{i}\right)}(i=1,2,3),
\end{aligned}
$$

$u\left(\vec{a}_{i}\right)$ is increasing and convex with

$$
A_{i}, B_{i}, C_{i}>0(i=1,2,3) \text {. }
$$

Now, instead of

$$
f\left(\left[w_{1} a_{j 1}+b_{1}\right]+\left[w_{2} a_{j 2}+b_{2}\right]+\left[w_{3} a_{j 3}+b_{3}\right]\right),
$$

we have

$$
f\left(u_{1}\left(a_{j 1}\right)+u_{2}\left(a_{j 2}\right)+u_{3}\left(a_{j 3}\right)\right) .
$$

The new objective is

$$
\min \frac{1}{8} \sum_{j=1}^{8}\left(g_{j}-f\left(u_{1}\left(a_{j 1}\right)+u_{2}\left(a_{j 2}\right)+u_{3}\left(a_{j 3}\right)\right)\right)^{2},
$$

and the new optimization problem is

$$
\begin{array}{ll}
\min & \frac{1}{8} \sum_{j=1}^{8}\left(g_{j}-f\left(\sum_{i=1}^{3}\left(C_{i} \log \operatorname{sig}\left(A_{i} a_{j i}+B_{i}\right)\right)\right)^{2},\right. \\
\text { s.t. } & A_{i}, B_{i}, C_{i} \in R, A_{i}, B_{i}>0,(i=1,2,3) .
\end{array}
$$

\section{ARTIFICIAL NEURAL NETWORK MODEL OF INVESTMENT DISTRIBUTION}

As the gross output of products is influenced by investment structure directly, in this paper we mainly study on the relations between the distribution of investment and output of products. To avoid learning spillover from input and output variables which are excessively large initially, we first standardize all the original data. Here, Z-Score transformation is selected:

$$
Z^{\prime}=\frac{Z-\bar{Z}}{S}
$$

where $\bar{Z}$ and $\mathrm{S}$ are the mean and standard deviation of $Z$, $Z^{\prime}$ is the value after transformation.

Then we create the artificial neural network and determine the relations between the distribution of investment and gross output of products. The main steps of modeling process are concluded in Fig. 2.

Here, the BP ANN is the one which has been improved in Section III. Various training methods are applied to train the network after system parameters are initialized and the best one is selected to reach the performance goal. Then the original data from the year 1996 to 2003 are used to simulate in the network. We use inverse transformation of Z-Score to calculate gross output values, then compare them with true values, and take the ones which have minimum errors and take fewest epochs for training.

The process to determine the optimal distribution is presented as follows:

Step 1: Adjust investment values on different industries in a range under the condition of invariable sum of each year.

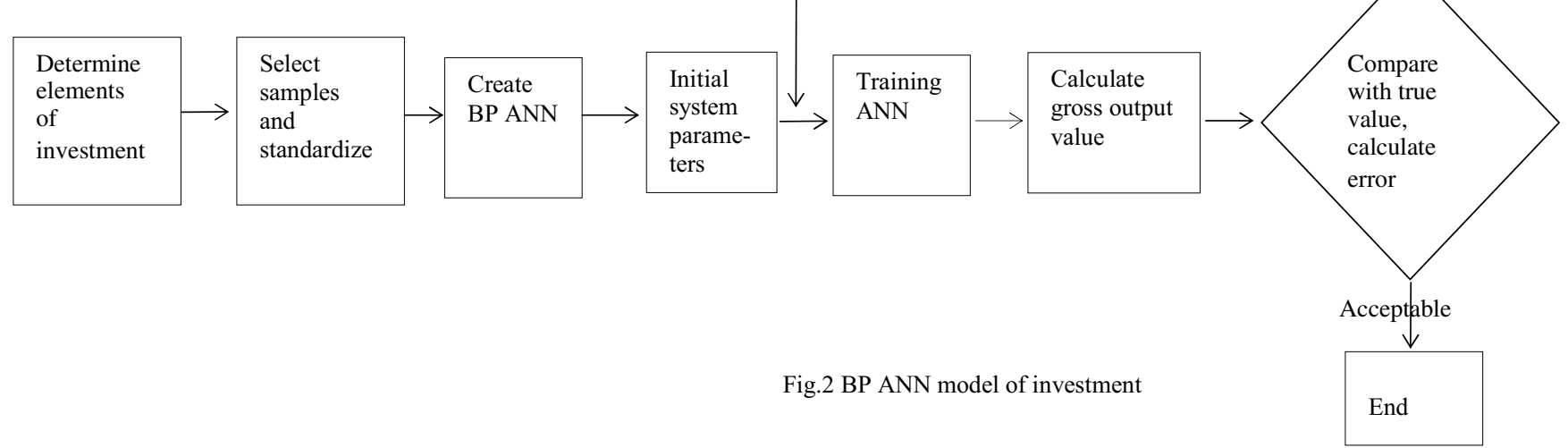


Step 2: Use the BP ANN to calculate all the combinations of investment distribution and get the gross output values.

Step 3: Compare all the values and record maximum ones.

As growth in different industries is relatively stable in TABLE I, the adjustment range is less than $10 \%$ of each investment value.

\section{MODEL APPLICATION AND ANALYSIS}

According to various training methods, accuracy is considered primarily. Training epochs and training time take the second place. In this problem, LM (Levenberg-Marquardt) algorithm is appropriate. It can offer high accuracy but take few epochs.

After calculation, training epochs are 44. TABLE III shows the calculated and true values for 8 years. Observations in TABLE III indicate that the calculated values are close to the true ones. The maximum error is $0.063 \%$. Hence, the model is suitable for this investment problem.

TABLE III

Calculated and true values

\begin{tabular}{|c|c|c|c|c|}
\hline Year & 1996 & 1997 & 1998 & 1999 \\
\hline Calculated values & 2380.8 & 2531.2 & 2766.1 & 3021.1 \\
\hline True values & 2380.9 & 2531.8 & 2765.7 & 3021.3 \\
\hline Year & 2000 & 2001 & 2002 & 2003 \\
\hline Calculated values & 3299.9 & 3604.9 & 3937.8 & 4299.8 \\
\hline True values & 3300.5 & 3605.5 & 3938.6 & 4302.5 \\
\hline
\end{tabular}

\section{Determine the OPTIMAL Distribution AFTER ADJUSTING THE INVESTMENT STRUCTURE}

Now we adjust investment values on different industries under the condition of invariable sum of each year. The range is less than $10 \%$ of each industry, namely, $-10 \%$ to $10 \%$. In this range investment values are put into $n$ parts $(n=20)$ averagely, each part is $1 \%$. Then we can use the trained ANN to calculate all the combinations of investment distribution and get the calculated gross output values for each year. At the end, all these values are compared. The maximum one is recorded and its position is also marked in the year. TABLE IV shows the results of the simulation. TABLE V shows the maximum gross output values and true values. Observations in TABLE $\mathrm{V}$ indicate that the result is perfect.

TABLE IV

Optimal distribution and maximum gross output

\begin{tabular}{|c|c|c|c|c|c|}
\hline \multirow{2}{*}{ Year } & \multicolumn{4}{|c|}{ Investment } & \multirow{2}{*}{ Gross output } \\
\cline { 2 - 5 } & 1st industry & 2nd industry & 3rd industry & sum & \\
\hline 1996 & 33.9 & 312.4 & 222.3 & 568.6 & 2426.2 \\
\hline 1997 & 42.8 & 368.1 & 259.0 & 669.9 & 2658.3 \\
\hline 1998 & 55.9 & 303.4 & 442.3 & 801.6 & 3544.7 \\
\hline 1999 & 64.0 & 277.3 & 444.6 & 785.9 & 3700.7 \\
\hline 2000 & 45.3 & 385.4 & 428.5 & 859.2 & 3422.7 \\
\hline 2001 & 60.4 & 385.1 & 533.2 & 979.7 & 3843.0 \\
\hline 2002 & 78.9 & 403.9 & 603.5 & 1086.3 & 4182.4 \\
\hline 2003 & 91.5 & 457.3 & 692.2 & 1241.0 & 4859.1 \\
\hline
\end{tabular}

TABLE V

Maximum and true values

\begin{tabular}{|c|c|c|c|c|}
\hline Year & 1996 & 1997 & 1998 & 1999 \\
\hline Maximum values & 2426.2 & 2658.3 & 3544.7 & 3700.7 \\
\hline True values & 2380.9 & 2531.8 & 2765.7 & 3021.3 \\
\hline Year & 2000 & 2001 & 2002 & 2003 \\
\hline Maximum values & 3422.7 & 3843.0 & 4182.4 & 4859.1 \\
\hline True values & 3300.5 & 3605.5 & 3938.6 & 4302.5 \\
\hline
\end{tabular}

\section{Conclusions}

An investment decision model is established by using an improved BP ANN in this paper. Nonlinear utility functions for fitting economic data are used to improve the architecture of artificial neural network during the modeling process. Calculation results after the comparison with the true values indicate that the improved BP ANN model to this problem is suitable. Maximum gross output value is reached by adjusting the distribution rationally, and then the optimal distribution of investment is determined at the same time. The model can not only reflect the highly nonlinear mapping relations among each element of investment but also determine the optimal investment distribution. In this way we develop an effective decision support technique for further investment and economic growth.

\section{REFERENCE}

[1] Wenjin Yang, Zhigang He, Investments, Beijing: Tsinghua University Press, 2004

[2] Leqin Luo, Zecong Chen, Investment Economics, Beijing: Science Press, 2003, pp.20-28.

[3] Richard Butler, Les Davies, Richard Pike, John Sharp, "Strategic Investment Decision-making: Complexities, Politics and Processes," Journal of Management Studies, Volume 28, Issue 4, May 2007, Pages 395-415.

[4] Haim Levy, Stochastic Dominance: Investment Decision Making under Uncertainty, New York: Springer, 2006

[5] M. Zeng, B. Hua, J. Liu, X. Xie, C. Hui, "Investment Decision-making for Optimal Retrofit of Utility Systems," Computer Aided Chemical Engineering, Volume 15, Part 1, 2003, Pages 382-387.

[6] Kjetil Emhjellen, Magne Emhjellen, Petter Osmundsen, "Investment Cost Estimates and Investment Decisions," Energy Policy, Volume 30, Issue 2, January 2002, Pages 91-96.

[7] Werbos P, Beyond Regression: New Tools for Prediction and Analysis in the Behavioral Sciences, Ph D Dissertation, Harvard University, 1974.

[8] Pramod Gupta, Naresh K. Sinha, "An Improved Approach for Nonlinear System Identification using Neural Networks," Journal of the Franklin Institute, Volume 336, Issue 4, May 1999, Pages 721-734.

[9] Iebeling Kaastra, Milton Boyd, "Designing A Neural Network for Forecasting Financial and Economic Time Series," Neurocomputing, Volume 10, Issue 3, April 1996, Pages 215-236.

[10] Fernando Fernández-Rodríguez, Christian González-Martel, Simón Sosvilla-Rivero, "On the Profitability of Technical Trading Rules Based on Artificial Neural Network: Evidence from the Madrid Stock Market," Economics Letters, Volume 69, Issue 1, October 2000, Pages 89-94.

[11] Weigend, Andreas S., "Paradigm Change in Prediction," Philosophical Transactions: Physical Sciences and Engineering, Volume 348, Issue 1688, September 1994, Pages 405-418.

[12] Xiaojun Bi, Dili Wen, "A Model for Investment Based on Synergetic Neural Network," CAAI-11, October 2005.

[13] Li Zhang, Aiping Yang, Wenzhan Dai, "Investment Decision-making Based on Fuzzy and Artificial Neural Network," ICNC 2007, Volume 3, August 2007, Pages 297-300. 
[14] Guangyi Yang, Jihong Shen, Xiaojun Bi, "Embedded Grey System Artificial Neural Network Method to the Investment Decision-making," Journal of Harbin Engineering University, Volume 27, July 2006, Pages 164-168.

[15]Martin T, Hagan, Howard B.Demuth, Mark H Beale, Neural Network Design, Beijing: China Machine Press, 2002.

[16] Winston, P.H., Artificial Intelligence, $3^{\text {rd }}$ ed., Reading MA: AddisonWelley, 1992. 